\title{
Epidemiology of Type 1 Diabetes mellitus in Mauritius
}

\section{Pravesh GUNESS, Marie CHAN SUN}

Faculty of Science, University of Mauritius, Réduit, Mauritius

\section{Email address:}

lan.sun@uom.ac.mu (M. C. SUN)

\section{To cite this article:}

Pravesh GUNESS, Marie CHAN SUN. Epidemiology of Type 1 Diabetes Mellitus in Mauritius. American Journal of Health Research. Vol. 1, No. 2, 2013, pp. 32-35. doi: 10.11648/j.ajhr.20130102.12

\begin{abstract}
There is increasing concern for the rising incidence of Type 1 Diabetes mellitus worldwide. In Mauritius, there is no official data on the incidence of this disease. On the other hand, the recent creation of a two non-governmental organizations in less than five years to support patients calls for a situational analysis of the disease. Therefore, this research work has been designed with the aim to appraise the epidemiology of Type 1 Diabetes mellitus in Mauritius. Epidemiological data of all Type 1 diabetic patients $\leq 14$ years of age was collected by means of a questionnaire comprising mainly of closed ended questions. This questionnaire was subject to a prior pilot study. Ethical clearance was obtained from the Ethics Committee of the local health authority. The age-standardized average incidence, for the period under scrutiny, was 4.94/100000/year. In boys and girls, it is 4.59 and 6.63/100000/year respectively. Referring to age of onset, it was observed that in male patients, the highest peak was observed at the age of 7 and 12 years whereas in female cases, the highest peak was observed at the age of 10 years. The median age at diagnosis for male and female patients was 8.02 and 10.0 years respectively. Being given the high incidence of T1D in Mauritius and the global rising trend, the surveillance of this disease needs to be addressed.
\end{abstract}

Keywords: Type 1 Diabetes Mellitus, Epidemiology, Incidence, Mauritius

\section{Introduction}

There is increasing concern for the rising incidence of Type 1 diabetes mellitus (T1D) worldwide [1]. In Mauritius, there is no official data on the incidence of T1D for the last five years. On the other hand, the recent creation of a two non-governmental organizations in less than five years to support T1D patients calls for a situational analysis of the disease. Therefore, this research work has been designed with the aim to appraise the epidemiology of T1D in Mauritius. The objectives of the study are to determine the incidence of T1D in Mauritius among patients $\leq 14$ years of age during the period 2004 - 2008 and to investigate its demographic characteristics in Mauritius over the 5-year period.

\section{Methods}

\subsection{Study Design}

This is a longitudinal study whereby epidemiological data of all Type 1 diabetic patients $\leq 14$ years of age was collected by means of a questionnaire comprising mainly of closed ended questions. This questionnaire was subject to a prior pilot study.

\subsection{Study Population}

The inclusion criteria for the study were: Mauritian patients diagnosed with $\mathrm{T} 1 \mathrm{D} \leq 14$ years of age from $1^{\text {st }}$ January 2004 to $31^{\text {st }}$ December 2008, and following treatment in one of the five public hospitals or in the private sector of the health system in Mauritius.

\subsection{Data Collection}

Data was collected by means of the survey instrument, which was filled by principal investigator with the collaboration of doctors. Anonymity and confidentiality of data were ensured throughout the process. Ethical clearance was obtained from the Ethics Committee of the local health authority.

In the public sector, the identification of all cases of T1D patients $\leq 14$ years of age diagnosed during the period 2004-2008 was performed with the involvement of the of the Chief Medical Record Officers and Non-Communicable Disease Secretariat of the five regional hospitals of Mauritius.

In the private sector, the identification of T1D cases was 
done with the collaboration of all paediatricians. The participation of the only diabetologist of the island was sought so as to ensure inclusion of all cases of T1D under study.

\subsection{Data Processing and Analysis}

Data entry, interpretation and statistical analysis were done on Epi Info ${ }^{\mathrm{TM}}$ Version 3.3.2. Microsoft Excel (Office 2007) was used to create the tables and charts.

\section{Results}

\subsection{Profile of Patients}

This research work showed that there were 71 new cases of T1D during the period 2004-2008. Table 1 shows the demographic data of the participants. There were 8 cases from the private sector and the remaining distributed among the 5 public hospitals in Mauritius. Minimum age at diagnosis was 1 year and maximum age was 14 years with a median age of 10 years (Standard deviation: 3.82 ). The interquartile range was 6.00 .

\subsection{Incidence}

The age-standardized average incidence, for the period $2004-2008$, is 4.94/100000/year. In boys and girls, it is 4.59 and 6.63/100000/year respectively. Table 2 shows the Age-specific and Age-standardised average incidence of T1D in Mauritius for the period 2004-2008.

\subsection{Age Group and Gender}

Figure 1 shows the distribution of male and female patients in each age-group. Referring to the frequency of male \& female patients with respect to age of onset, it was observed that in male patients, the highest peak was observed at the age of 7 and 12 years whereas in female cases, the highest peak was observed at the age of 10 years. The median age at diagnosis for male and female patients was 8.02 and 10.0 years respectively.

\subsection{Ethnicity}

The frequency of T1D among Indians and Africans were 45 and 26 respectively. There were no incident cases of Chinese or European origin.

\subsection{Seasonal Variation}

The minimum number of cases was observed in March and December whereas the maximum number of cases was observed in May and June.

\subsection{Family History}

There was neither Type 1 nor Type 2 Diabetes mellitus in first-degree relatives in $85 \%$ of cases. Out of the 71 cases, there was one case where both parents have T1D and another where the mother has T1D. In one case, both parents have T2D.

\section{Discussion}

\subsection{Incidence}

The incidence of T1D is increasing worldwide, both in low and high incidence populations [2]. The WHO Multinational Project for Childhood Diabetes (DiaMond Project) and the EURODIAB ACE collaborative Study [3], which confirms this worldwide trend, support our findings.

The incidence obtained from this study is the highest ever recorded in Mauritius, as it shows that the age-standardized average incidence rate in Mauritius is 4.94/100000/year. Previously, Tuomilehto et al (1993) had established that the average age-standardized incidence density (among children $\leq 14$ years) was $2.1 / 100000$ respectively in Mauritius [4]. Karvonen et al (2000) had reported that from 1990 to 1994 the age-standardized incidence per year was $1.3 / 100000$ in boys and $1.5 / 100000$ in girls [5]. On the other hand, IDF estimated incidence of T1D among Mauritian children (0-14 yrs) in 2003 is $1.4 / 100000 /$ year [1].

This study clearly demonstrates that Mauritius is among those countries, which are experiencing a rise in the number of T1D during the past 20 years. The average incidence, obtained from this study, shows that Mauritius has the highest rate in the South-East Asian region [1]. The incidence obtained from this study could not be compared to other African countries due to the unavailability of incidence rates in these countries.

It is to be pointed out that one of the strength of this research work is that data was compiled from both the public and private sector and has involved the collaboration of all paediatricians of the country. So far, data pertaining to diabetes in Mauritius has been derived from the public sector only. It is crucial to get data from the private sector as well, so as to get a holistic vision of the situation of T1D in Mauritius. This study has shown that most cases that are diagnosed by paediatricians exercising in the private sector are immediately referred to hospitals. Great care was taken to avoid overlapping of data collection.

The reasons put forward for referral are that the treatment of T1D, which includes cost of insulin, test strips, glucometer and syringes, is too expensive in the private sector. Moreover, the management of $\mathrm{T} 1 \mathrm{D}$ is a multidisciplinary one, involving the participation of paediatrician, nutritionist, psychologist, health assistant and endocrinologist. These combined facilities are not easily accessible in the private sector.

In Mauritius, there are two non-governmental organizations, namely T1Diams and Diabetes Parent Support Group, which aim at providing holistic care to T1D patients, supporting patients and their relatives as well as raising awareness on T1D among the Mauritian population. The creation of these two non-governmental organizations in less than five years clearly demonstrates the need of 
patients with respect to the holistic approach required for the management and monitoring of the disease.

\subsection{Age at Onset}

The variation in the age at onset is relatively constant worldwide [6]. It has been reported that the age at diagnosis follow a bimodal distribution [7] with a peak incidence at 0-4 years [8] [9] and one at early adolescence and puberty [10] [6]. Although it was suggested that the age at diagnosis follows a bimodal distribution [7], no such observation was made in this study.

On the other hand, the findings of this study are in line with the observation of Lévy-Marchal et al (1992) [10] as the maximum number of cases occurred in the age-group $10-14$ years. A possible explanation is the fact that it is during this period that children are admitted to colleges. Gamble and Taylor (1969) highlighted that the change in environment, from primary to secondary school, which may result in the exposure to new infections, could partly explain this peak [11]. However Aumeer (2007) has not noted any peaks in the number of cases in childhood or in adolescence but a peak in the age group 5.0-9.9 years [12].

\subsection{Gender}

In this study, the ratio for male to female patients is nearly the same in both sexes. This is in line with Tuomilehto et al (1993) who observed the same ratio in the study that they carried out in Mauritius in 1993 [4]. According to the DiaMond Project, the male to female ratio varies among lower-risk and higher- risk populations [3]. Those countries having a low incidence of the disease tend to have a small surplus of female than male patients and vice-versa in countries of high incidence [13].

\subsection{Ethnicity}

The DiaMond Project and the EURODIAB ACE Study have provided clear evidence that racial and ethnic background represents one of the most important risk factors for T1D [3] [14]. Moreover, the DiaMond Project has shown that this disease is rare in most African, American Indian, and Asian populations i.e. non-white populations [3] [14]. However, this research work shows that most patients in our study are of Indian and African origin.

\subsection{Seasonal Variation}

It has been observed that there is a seasonal pattern in the onset of T1D [11]. Studies have shown that, in the northern and southern hemispheres, the number of new cases of T1D is low during the warm summer months compared to the whole year [15] [6] [16]. This study reports the same observation whereby the minimum number of cases per year was observed in March and December, which corresponds to summer in Mauritius. The maximum number of cases was observed in May and June, which coincides with the change from hot to cool season in
Mauritius. This is in line with Zhao et al (1999) who showed that the peak incidence was in autumn and winter in the far South-West of England [17].

\subsection{Family History of the Patient}

The WHO DiaMond Project Group (1991) \& Spielman et al (1980) have reported that about 80 to $90 \%$ of cases occurs in people with no family history of T1D [18] [19]. The same trend is observed in this study, as there was no family history of diabetes in $85 \%$ of cases.

\subsection{Strength and Limitation}

This study has produced epidemiological data on T1D in Mauritius by the investigation of cases from both the public and private health sector of Mauritius. This is the main strength of this research work, as this has never been achieved in previous studies on the incidence of the disease in Mauritius. However, we acknowledge one limitation encountered in this study: diabetes registries were not up-to-date in four of the five public hospitals. Intensive search of patients' files had to be performed with the involvement of medical and para-medical staff in paediatric and medical wards of these hospitals.

\subsection{Recommendations}

In light of the above, the first recommendation emanating from this study is the need for computerization of data of all regional hospitals so as to constitute a national register for T1D. It is also recommended that future epidemiological studies be continued in order to monitor the incidence and/or the prevalence of T1D in Mauritius.

\section{Conclusion}

The age-standardized average incidence rate of T1D in Mauritius is 4.94/100000/year. The incidence of T1D from both the private and public health sector of Mauritius, which was not available previously, now constitutes baseline data. Being given the high incidence of T1D in Mauritius and the global rising trend, the surveillance of this disease needs to be addressed. Epidemiological data and recommendations from this research work will empower health authorities and non-governmental organizations to adopt strategies for the surveillance of the disease in Mauritius. As future initiative, epidemiological studies with respect to prevalence of the disease needs to be explored in Mauritius.

\section{References}

[1] IDF, 2005. Estimates of type 1 diabetes in children South-East Asian Region [online]. Belgium, IDF. Available from: http://www.eatlas.idf.org/Incidence [Accessed on 15 October 2008].

[2] P. Onkamo, S. Vaananen, M. Karvonen and J. Tuomilehto, 
1994. Worldwide increase in incidence of Type 1 diabetes the analysis of the data on published incidence trends. Diabetologia, 42:1395-1403.

[3] WHO Diamond Project Group, 1990. WHO multinational project for childhood diabetes. Diabetes Care, 13:1062-68.

[4] J. Tuomilehto, J. Dabee, M. Karvonen, G. K. Dowse, H. Gareeboo, E. Virtala, M. Tihonen, K.G.M.M. Alberti, and P.Z. Zimmet, 1993. Incidence of IDDM in Mauritian children and adolescents from 1986 to1990. Diabetes Care, 16(12).

[5] M. Karvonen, M. Viik-Kajander, E. Moltchanova, I. Libman, R. Laporte and J. Tuomilehto, 2000. Incidence of childhood type 1 diabetes worldwide. Diabetes Mondiale (DiaMond) Project Group. Diabetes Care. 23(10):1516-26.

[6] R.E. Le Porte, N. Tajima, J.S. Durman et al., 1986. Differences between blacks and whites in the epidemiology of insulin dependent diabetes mellitus in Allegheny County, Pennsylvania. Am J Epidemiol, 123: 592-603.

[7] A.N. Hussain and M.T. Vincen, 2007 Diabetes Mellitus, Type 1[online]. WebMD. Available from: http://www.emedicine.com/med/TOPIC546.HTM [Accessed 28 October 2008].

[8] V. Harjutsalo, G.L. Sjöber and J. Tuomilehto, 2008. Time trends in the incidence of type 1 diabetes in Finnish children: a cohort study. Lancet, 371(9626), 1777-82.

[9] M. Karvonen, J. Pitkäniemi and J. Tuomilehto, 1999. The onset age of type 1 diabetes in Finnish children has become younger. The Finnish Childhood Diabetes Registry Group. Diabetes Care, 22(7), 1066-70.

[10] C. Levy-Marchal, L. Papoz, C. De Beaufort, J. Doutreix, V. Froment, J. Voirin, P. Czernichow, 1992. Clinical and laboratory features of type 1 diabetic children at the time of diagnosis. Diabetic Medicine, 9(3):279-84

[11] D.R. Gamble and K.W. Taylor, 1969. Seasonal incidence of diabetes mellitus. Br Med J, 3: 631- 633 .

[12] N. Aumeer, 2004. Diabète De Type 1 Chez L'Enfant De Moins De 17 Ans A Maurice Aspects De La Prise En Charge. Mémoire. Mauritius Institute of Health.

[13] M. Karvonen, M. Pitkäniemi, J. Pitkäniemi, K. Kohtamäki, N. Tajima and J. Tuomilehto, For The World Health Organization Diamond Project Group, 1997. Sex difference in the incidence of insulin-dependent diabetes mellitus: an analysis of the recent epidemiological data. Diabetes Metab Rev, 13:275-291.

[14] A. Green, E.A.M. Gale and C.C. Patterson, 1992. Incidence of childhood onset insulin-dependent diabetes mellitus: The EURODIAB ACE study. Lancet, 339:905-09.

[15] G. Joner and O. Sovik, 1989. Increasing incidence of diabetes mellitus in Norwegian children $0-14$ years of age 1973-1982. Diabetologia, 32:79-83.

[16] H.A. Fishbein, R.E. Laporte, T.J. Orchard et al., 1995. The Pittsburgh insulin-dependent diabetes mellitus registry: Seasonal incidence. Diabetologia 23:83-85

[17] H.X. Zhao, E. Stenhouse, C. Soper, P. Hughes, E. Sanderson, J.H. Baumer, A.G. Demaine and B.A. Millward,1999. Incidence of childhood-onset Type 1 diabetes mellitus in Devon and Cornwall, England, 1975-1996. Diabetic Medicine, 16 (12), 1030 - 1035.

[18] WHO Diamond Project Group, 1991. Familial IDDM epidemiology: Standardization of data for the DIAMOND Project. Bull WHO, 69:767-77.

[19] R.S. Spielman, L. Baker, C.M. Zmijewski, 1980. Gene dosage and susceptibility to insulin dependent diabetes. Ann Hum Gene, 44:135-150. 